\title{
Discussion on Connotation and Educational Function of Music Culture in Yanzhao Area
}

\author{
Jing Sun \\ School of Music \\ Langfang Teachers University \\ Langfang, China
}

\begin{abstract}
Yanzhao culture is a kind of regional culture formed in Yanzhao area, which is one of the important birthplaces of Chinese traditional culture and bears thousands of years of development history of Chinese civilization. The formation of Yanzhao music culture has unique regional characteristics and it is formed under specific historical conditions. So deeply researching the connotation of Yanzhao music culture helps to better promote the inheritance and development of our traditional culture. This article firstly discusses the development venation of Yanzhao music culture, and then analyzes its connotation and forms, and finally deeply discusses functions that Yanzhao music culture has on modern music education. The author hopes that it can bring certain reference value to the research on Yanzhao culture.
\end{abstract}

Keywords-Yanzhao music culture; development venation; connotation and characteristics; educational function

\section{INTRODUCTION}

The development history of five thousand years of civilization of Chinese culture is just like an old tree that has deep roots and luxuriant leaves and brings strong historical foundation for the development of Chinese culture. Music culture can be compared to the root system that stretches outward and absorbs sunshine for the growth of the old tree. From ancient times to the present, China is always a country with vast land and many nationalities. Different regional cultures of nations jointly form the treasure-house of pluralistic development of Chinese culture. Yanzhao culture is one of the mainstream cultures developed in pre-Qin period and an important part of the development of Chinese civilization. Yanzhao music culture is an important part of Yanzhao culture. Under the background that we continue to carry forward traditional culture and inherit regional civilization, it is imperative to research Yanzhao music culture. The development of a country can't do without the support of traditional culture, which has increasingly become an important factor to concentrate the power of Chinese and inherit humanistic spirits. Therefore, the research on Yanzhao music culture can not only promote the inheritance and development of traditional culture, but also help to cultivate people's tastes and enlighten their wisdom.

\section{HistoricAl DEVELOPMENT OF YANZHAO MUSIC CUlture}

\section{A. Development of Yanzhao Music Culture in Budding Stage}

At the budding stage of development of Yanzhao music culture, the culture of music and dance in the period of slavery society appeared. The concept of class in slavery society is at its budding stage. The music accompanied by dance at that time was mainly used in worship ceremonies and invocation. In the Shang dynasty, people in Yanzhao area produced the unique culture of music and dance of poetry style. The music accompanied by dancing is mainly divided into two types. One is the music used in Wen dance, the other is the music used in Wushu dance. The forms of the two kinds of music have close relations. Generally, the Wushu dance is used in the opening of a show while the Wen dance is used in the last. In Western Zhou dynasty, the most famous is rites and music culture. Later when it came to six dynasties, the culture of music and dance integrated songs, dance and music, and the scale got increasingly larger. In pre-Qin period, the Zhou dynasty perished, and there was continuous social upheaval and it appeared the situation of "propriety disintegration". The system of rites and music is broken gradually. The original musicians in the palace have to go to the folk to make a living. So it appears the condition of "degradation of culture", which promote the gradual development of folk music.

\section{B. Yanzhao Music Culture in Golden Age}

The representative type of Yanzhao music in the golden age is singing and dancing music. During Qin and Han dynasty, "cheerful music of Chu State" appeared. Folk music was gradually accepted by the governor. The folk music integrated with refined music. When it came to the Period of Wei, Jin and Southern and Northern Dynasties, with the decay of Jin dynasty, northern ethnic minorities such as Xianbei nationality and Hun moved down to the south, which caused the phenomenon that the Han people coexisted with $\mathrm{Hu}$ people in Yanzhao area. Continuous conflicts between nationalities strengthened the integration of ethnic cultures and promoted the wide spread of Buddhist music culture in Yanzhao area. In Tang dynasty, the development of music culture presented all-embracing style and the style 
of music was changed greatly. At this time, the fusion of the Han people and $\mathrm{Hu}$ people in Yanzhao area become increasingly closer, which makes the folk music and $\mathrm{Hu}$ music in Yanzhao area enter the golden age in the flourishing period of the Tang Dynasty.

\section{The Decay and Inheritance of Yanzhao Music Culture}

After the Song dynasty, folk music gradually became the mainstream music in society. The form and content of music were closer to people's life. The culture of song and dance decayed gradually from the mainstream culture and it was replaced by traditional opera culture that had regional characteristics. In early period of the Northern Song dynasty, "words and music with elegant melody" became the mainstream of Yanzhao music. In later period of the Northern Song dynasty, the original royal music was gradually scattered to the folk and forms music culture and art that were closer to people's life. In the Yuan dynasty, the culture of song and dance decayed gradually because of suppression of the governor. But on this basis, it formed Yuan $\mathrm{Qu}$, which spread more widely. At that time, many musicians and music works appeared in Yanzhao area, such as Snow in Midsummer of Guan Hanqing, Romance of the Western Chamber of Wang Shifu, etc. All of them are typical representative works of Yanzhao music culture at this period. In later period, the rap music and Gong Diao music got development, such as Zhu Gong Diao of Tian Bao's Incidents of the Past created by musician Wang Bocheng. When it came to the Ming and Qing dynasties, Yanzhao music also kept up with the trend of the development of times. Folk music and Xiaoling got spread and development, such as the famous Hexi Tune in northern Baiyang Lake and Qingjiang Yin in local Cangzhou. [2]

\section{Connotation OF YANZhaO Music CUlture}

Analysis on connotation of Yanzhao music culture actually involves many aspects of contents. The definition, development history and significance of development of Yanzhao music culture all embody the research value of Yanzhao music culture. The first person who defines Yanzhao culture is Si Maqian in the Han dynasty. He defined Yanzhao music culture as cultural characteristics of "Magnificent and Pessimistic Songs". Ban Gu in later period also continued to use this word to define Yanzhao culture. Most of literati also agreed with this opinion and took the magnificent and pessimistic characteristic as the pronoun of Yanzhao culture. Until today, many research scholars summarize the connotation of Yanzhao culture as "chant in a heroic but mournful tone, gallant and chivalrous" to show its cultural characteristics. This kind of cultural connotation has its unique cultural features and is different from other traditional regional cultures. Next we will deeply analyze the connotation of Yanzhao music culture in three aspects.

\section{A. Impassioned Heroic Melody}

The main connotation characteristics of Yanzhao music culture can be summarized as "chant in a heroic but mournful tone, gallant and chivalrous". So the impassioned connotation characteristic is the theme of Yanzhao music culture. The form of this characteristic has close relationship with unique regional characteristics of Yanzhao area. The land form in Yanzhao area is very complicated. The northern area is highland, which is nomadic and semi-nomadic area; while most of the middle areas are mountain land and hills, which are good for farming and hunting; the southern area is plain, which is used for farming. The regional characteristic forms farming culture and nomadic culture in Yanzhao area. Influenced by the reform of emperor Xiaowen of Northern Wei dynasty, these two cultures jointly form Yanzhao culture through integration and reference in continuous exchange and development. Meanwhile, the climate in this area is humid and rainy and the vegetation in this area is flourishing. People are good at riding and shooting. Through continuous historical inheritance, people in Yanzhao area formed their adventurous, hardworking and plain-living and dedicated cultural characters, which make the melody of music present the impassioned characteristics. For example, the Peking Opera, Farewell to My Concubine and the libretto and melody of the famous folk song, Little Buffalo Cowboy, embody this characteristic.

\section{B. Chivalrous and Tender Music Quality}

The chivalrous and tender characteristics embodied by Yanzhao music culture is formed on the basis of historical development. On the whole, looking from the history of formation of Yanzhao culture, Zhao Culture derives from Sanjin period. Jin people have unique chivalrous spirits, which can be proved in deeds of literati and chivalrous person recorded in ancient books. For example, in the period when Zhao Shuo is the emperor, the story is widely spread that Gongsun Chujiu and Cheng Ying sacrifice their lives in order to protect the descendant of Zhao people; in the period when Zhao Yang is the emperor, Dong An bears all responsibilities for an offense for others and finally hangs himself and dies. All signs indicate that Zhao Culture is formed and influenced by chivalrous and tender ethos, which prompt many folk songs in Hebei to embody through this chivalrous music feature. While Yan culture derives from Yan. It bears the subjugation and turmoil of Shang dynasty and has bold and powerful and chivalrous characteristics. So the chivalrous and tender quality inherited by Yanzhao music culture also has its unique historical significance. [1]

\section{Express Words and Music of Patriotism and Loving Family}

In Yanzhao period, the chaos caused by war happened frequently and social contradiction was sharp. Before the reform in the Northern Wei dynasty, nomads in northern area often battled with farmers in the south; then the internal disputes of agriculture civilization and nomadic civilization were continuous; besides, nationalities within the region also had continuous wars. Wars became ordinary affairs in people's daily life. They got used to life and death, so they had unique perspectives on life. These people didn't pay attention to the length of life, but cared more about the significance of life. These conditions make the people in Yanzhao area brand the spirit of patriotism and loving family in overall national interest and then the unique Yanzhao culture formed. Under this historical background, the words 
and tune of Yanzhao music embody the theme of patriotism and loving family. For example, in the famous music Ballad of Mulan, the lyrics of "After ten thousand kilometers of riding, Mulan arrives at the battlefield, going over the mountains like flying" and "After hundreds of commanders and soldiers' sacrifice, heroes come back" profoundly reflect the regional characteristics that people in Yanzhao area love their country and families.

\section{Diligent and Practical Ethnic Characteristics}

Yanzhao music culture shows the diligent and practical characteristics of Hebei people. This also has close relationships with its unique historical inheritance. In Western Han dynasty, Dong Zhongshu has the diligent quality that "don't peek into the garden for three years"; in Sui and Tang dynasties, the Quhe Pond and Gushan Weir are built; and later people in Yanzhao area build the Great Wall. All of these reflect the diligent and practical characteristics of people in this area. The most important representative of music form is the produce of "work song". The work songs in Hebei are sung by laboring people impromptu and show people's optimistic and diligent attitudes towards life. For example, the Flood Fighting Work Song is the representative of work song in Hebei. It uses passionate and elevated melody and readable lyrics to stimulate people's mood to make efforts to fight the flood.

\section{EDUCATIONAL FUnCTION OF YANZHAO MUSIC}

\section{A. Pass on Traditional Culture}

The Eighteenth National Congress of the CPC once put forward the development strategy of national culture, namely "education should be regarded as the foundation; use culture to make our country prosperous". The development of traditional culture has become the important support for our national rejuvenation. Yanzhao culture has long history and existence value and unites cultural spirits of Chinese civilization from ancient times to the present. It is obvious to see its historical significance. The inheritance and development of Yanzhao culture can better promote the transmission and development of traditional culture. It has become the important driving force of national development to inherit historical spirit and carry forward the traditional culture. The inheritance of traditional culture can not only show Chinese characteristics, but also effectively gather Chinese spirit. Therefore, as an important part of our traditional culture, inheriting and renovating Yanzhao music culture in the process of continuous development will be more beneficial to pass on traditional culture. Taking the inheritance and development of Peking Opera as an example, many contemporary musicians combine Peking Opera with modern music, which have formed music art with unique cultural value.

\section{B. Promote Aesthetic Value}

The aesthetic value inherited by music mainly refers to that people can feel the values passed by their national music through traditional music and improve their aesthetic taste through appreciation of traditional music. Yanzhao area uses its long historical culture and rich music forms to pass colorful arts of music to us. For example, the Sheng pipe music in Hebei province, Hebei Clapper Opera and Sanzhihua in eastern Hebei province are the important inheritance forms of Yanzhao music culture. Through appreciation and learning of the music, it can promote the cultivation of people's aesthetic taste and make people deeply understand the connotation and characteristics of Yanzhao music culture, cause the resonance of thoughts and the senses of identification and pride in the beautiful and passionate melody and then improve the aesthetic value.

\section{Cultivate Thought and Sentiment}

Music is a form of activity that has creative characteristics since its appearance. It can enlighten people's thoughts and affect their feelings. Various forms of music can relieve people's mood as well as bring grief and indignation. In the process of inheritance, because of the rich historical accumulation and cultural value, Yanzhao music culture can go deeper into people's thoughts and heart and actually drive Chinese people's senses of identification for national culture, which help the sublimation and development of the whole national culture.

\section{Cultivate Innovative Thinking}

Actually, the generation of music has a long history and it is also the development of people's creative thinking. Music is the creative performance of people for activities in society. So music education can help to develop and expand the limitations of people's thinking, at the same time, it also strengthen the active degree of thinking. Therefore, fundamentally speaking, music education can promote the innovation of people's thinking. Continuous practical experience has indicated that as an important part of contemporary folk music education in China, Yanzhao music culture can effectively promote people's cooperative consciousness and creative spirit and then rapidly drive the development of innovative thinking of the whole nation. Therefore, in the future development, we should pay attention to the educational effects of Yanzhao music culture and drive Yanzhao music culture to carry forward in the continuous inheritance through continuous education practice.

\section{CONCLUSION}

Yanzhao music culture has a long history, embodies music characteristics in different historical periods of Chinese nation and is the imprint of civilization inherited by Chinese culture. At present, we should deepen the research on connotation of Yanzhao music culture. Only by doing this can we develop a broader development space for the inheritance of Yanzhao culture. The society should intensify the publicity and learning of Yanzhao culture, let it walk out of Hebei and move towards the whole nation and finally step on the world stage of culture and art. To effectively achieve these needs to offer course of Yanzhao music in colleges under the support of government. The local government also should make use of diversified media to reinforce the publicity of Yanzhao music culture. The most important 
thing is to drive the innovation and development of Yanzhao music culture under the premise of development of traditional music art.

\section{REFERENCES}

[1] Chang Jingjing. Research on the History and Inheritance of Yanzhao Music Culture under the View of National Music [J], Journal of Tangshan Normal College, 2014, (6):75-78

[2] Yang Qing, Zhang Lei. Overview on Seminar of Yanzhao Music Culture [J], People's Music, 2015, (3):48-49

[3] Gao Xiang, Chen Hui. Research on Development Strategy of Music Culture Resources--Take Resources of Yanzhao Music Culture as an Example [J], Yellow River of the Song, 2013, (21):16-17

[4] Chang Jiangtao. Inherit National Historical Tradition, Co-create New Era of Yanzhao Music--Comment on "Seminar of Yanzhao Music Culture" [J], Music Research, 2014, (6): 106-111,118 